in the workplace, it has achieved remarkable results. Therefore, we will expand this system further throughout incentives in reduction of Preventive rates, exemption of supervision, and facility improvement fund support, etc.

\section{HOW TO MANAGE THE IMPACT OF MEGATRENDS ON THE WORLD OF WORK? - CHALLENGES AND PROSPECTS}

Sabine Herbst*. German Social Accident Insurance (DGUV), Sankt Augustin, Germany

\subsection{6/oemed-2018-ICOHabstracts.67}

Introduction New trends like globalisation, digitalization, demographic change and social changes characterised by increasing migration and diversity are changing the world of work rapidly. This leads to new demands on employees, with the emergence of new safety and health risks. What are the new risks associated with current and imminent changes in the working environment? And how can occupational safety and health address them?

Methods Work 4.0 will need a Prevention 4.0. DGUV has therefore started research into new forms of work and risks caused by different megatrends on the one hand and monitoring possible future risks for safety and health at work in order to prevent or at least minimise them on the other hand.

Results The following examples show the development observed by the experts

- New forms of work and flexibility of work

- New technologies

- Communication between humans and communication between humans and robots

- New expectations of leadership

- Forms of learning and learning locations

- Skills and behaviour

In addition, DGUV identified prevention priorities with its Risk Observatory at an early stage. In October 2016, as a result of a consultation with some 400 inspectors of the social accident insurance institutions, ten topics were identified which will be important for the prevention work of the social accident insurance in the next five years. Sector-specific measures to face the risks were also identified. The Risk Observatory will start the next survey in 2017.

Discussion The presentation wants to show megatrends and their impact on the future world of work and the challenges for safety and health to avoid occupational accidents and injuries in future with focus on the results of the above mentioned research.

\section{A PILOT STUDY TO IDENTIFY THE FACTORS FAVOURINGHYPOVIGILANCE BY DROWSINESS MEASURED BY A NON-INVASIVE MONITORING DEVICE UNDER REAL CONDITIONS}

${ }^{1} \mathrm{M}$ El Fassi* ${ }^{2},{ }^{2} \mathrm{~J} J o r i s,{ }^{3} \mathrm{C}$ François, ${ }^{3} \mathrm{~J}$ Wertz, ${ }^{4} \mathrm{~L}$ Godderis, ${ }^{2} \mathrm{~A}$ Ghuysen. ${ }^{1} I D E W E$, external service for prevention and protection at work, Haasrode, Belgium; ' University of Liège, Liège, Belgium; ${ }^{3}$ Phasya, Liège, Belgium; ${ }^{4}$ University of Leuven, Centre for Environment and Health, Leuven, Belgium

\subsection{6/oemed-2018-ICOHabstracts.68}

Introduction Every year, more than one million people die on the road worldwide, $20 \%$ of these deadly accidents being caused by hypovigilance due to drowsiness.
Methods Our study tested the feasibility of monitoring the level of sleepiness under real driving conditions, using the non-invasive Phasya monitoring device. Data were collected in 24 bus drivers' records, from November 3 to December 15, 2016.

Continuous measurement of the level of drowsiness with Phasya device, allowed to scale this level from 0 (awake) to 10 (drowsy) by analysing ocular movements extracted from images of the eye.

In addition, we determined individual and occupational risk factors potentially associated with drowsiness. Individual variables included, biometric, health-related data and the sleep profile. Occupational factors included the duration and distance travelled.

Diurnal sleepiness was self-assessed with the Epworth Sleepiness Scale.

Results We recorded 31 journeys for a total of 6070 kilometres and 193 hours of driving.

The drowsiness monitored was greater than or equal to 5 over 10 in $11.98 \%$ of the data collected, which is equivalent to more than 23 cumulative hours and more than 700 kilometres travelled being drowsy.

Health behaviours such as regular physical activity and the absence of overweight showed non-significant protective patterns.

However, diurnal sleepiness was highly associated with the level of drowsiness $(r=0,74)(p=0,02)$. Likewise, the duration of journeys was also highly associated with increasing sleepiness $(r=0,25, p<0,0005)$.

Conclusion This study demonstrates that the Phasya monitoring device is able to measure drowsiness under real driving conditions. Our results emphasise the need for prevention campaigns to include early detection of risk factors, as well as optimising the care of drivers suffering from drowsiness.

We suggest that imposition of breaks based on drivers' drowsiness level and driving time. Giving a break after 2 hours of driving appears reasonable in terms of safety.

\section{OCCUPATIONAL SAFETY AND CONCUSSION INJURY AWARENESS OF IRISH PROFESSIONAL AND SEMI- PROFESSIONAL FOOTBALLERS}

${ }^{1} \mathrm{CJ}$ Buggy*, ${ }^{2} \mathrm{~N}$ Coffey, ${ }^{1} \mathrm{M}$ Lawless, ${ }^{3} \mathrm{~S}$ Kelly. ${ }^{1}$ Centre for Safety and Health at Work, School of Public Health, Physiotherapy and Sports Science, University College Dublin, Ireland; ${ }^{2}$ Shamrock Rovers Football Club, Tallaght Stadium, Dublin, Ireland; ${ }^{3}$ Centre for Sports Studies, School of Public Health, Physiotherapy and Sports Science, University College Dublin, Ireland

\subsection{6/oemed-2018-ICOHabstracts.69}

Introduction The purpose of the study was to investigate the occupational safety awareness of a cohort of professional athletes; specifically looking at the risk of concussion, reporting rates, and practices amongst professional and semi-professional footballers. Methods The study was an empirical quantitative study, in the form of a census, of a particular cohort $(n=250)$ conducted in 2015. Participants were professional or semi-professional footballers playing in the League of Ireland. Footballers undertook a questionnaire on safety awareness and self-reported concussion over the previous five playing seasons. 149 footballers participated $(60 \%$ response rate, $>90 \% \mathrm{CI})$. Data was analysed using SPSS.

Results Over two thirds of respondents were unaware if their football club had a formal safety programme. Results indicated footballers had little occupational safety awareness, though they felt that both management and teammates employed good safety practices. $32 \%$ of respondents stated they had 